\title{
Examination of Merricks' Primitivism about Truth
}

\author{
A. R. J. FISHER
}

\begin{abstract}
Trenton Merricks (2007) argues for and defends a novel version of primitivism about truth: being true is a primitive monadic but non-intrinsic property. This examination consists of the following triad: a critical discussion of Merricks' argument for his view, a rejection of his objection against Paul Horwich's (1998) minimalist theory of truth, and a direct objection against his view on the grounds that it entails being true is a mysterious and suspicious property. The conclusion is that Merricks' primitivism should be rejected.
\end{abstract}

Keywords Truth $\cdot$ Ontology $\cdot$ Non-relational Non-intrinsic Properties

\section{Introduction}

Theories of truth are often ambiguous between giving an account of the nature of truth and giving an analysis of the concept of truth. Theories of the latter are proposed in the following schema:

(C) for all $x, x$ is true iff $\ldots x \ldots$,

The correspondence theory fills in this schema as: for all $x, x$ is true iff $x$ corresponds to some fact (Moore 1953, 267-9; Russell 1912, 127). Other relational theories of truth such as coherence (Alcoff 1996) and pragmatist theories (James 1909) of truth offer similar analyses of the concept of truth in terms of the notion of coherence and utility respectively. Since these theories give an account of the concept of truth, let us call them conceptual accounts of truth. So if you declare that the concept of truth does not admit of analysis, you are a conceptual primitivist about truth. You think truth is conceptually unanalysable.

In contrast, theories that give an account of the nature of truth give an account of the property being true that is had by some propositions or truth-bearers and not others. ${ }^{1}$ They are proposed in the following schema:

(O) what it is for a truth to have the property being true is for it to stand in some more fundamental relation $R$ with some other entity.

The correspondence theory on an ontological construal posits a primitive relation of having correspondence to that holds between a truth and some fact. Similarly, coherence and pragmatist theories of truth posit the relation having coherence with and having some utility for respectively that in part grounds the property being true. Since these theories give an account of the property being true, let us call them ontological

\footnotetext{
${ }^{1}$ Throughout this paper I remain neutral about the nature of the bearers of truth, although I refer to truth-bearers as propositions. And sometimes I write propositions with angle brackets: the proposition that $\mathrm{p}$ is written as $<\mathrm{p}>$.
} 
accounts of truth. So if you declare that the property being true does not admit of analysis, you are an ontological primitivist about truth. You think truth is ontically unanalysable. Trenton Merricks (2007) has recently defended ontological primitivism about truth. He takes being true to be a primitive property that has a robust nature. It is monadic and non-intrinsic.

Given the concept of truth/being true distinction, we could take the concept and property as primitive or take the property but not the concept as primitive or perhaps give a conceptual and ontological analysis of both. It all depends on what you take your particular project of analysis to consist in. Some are concerned with conceptual analysis and others are focused on truth's underlying nature and hence concerned about ontological analysis. The latter concern requires us to be clear on what kind of property we think being true is or at least have some conception of properties as a background framework within which we present our ontological account of truth. The subject of truth in philosophy is a topic that we arrive at in media res. And as such it has its beginning and its end elsewhere.

To illustrate, consider the minimalist theory of truth as defended by Paul Horwich (hereafter minimalism). For Horwich, the concept of truth is primitive since he thinks the concept does not admit of analysis in the sense that there is no need for 'a specification (in philosophically unproblematic terms) of the content of every statement employing the concept' (Horwich 1998, 10). So if that is the project of analysis, then Horwich is a conceptual primitivist about truth in this particular sense. But Horwich is well aware that there is more to truth than our concept of it. According to Horwich, there is a property being true that is had by some propositions and not others. But he thinks it is not a substantive or naturalistic property or that it is constituted by more fundamental properties. Instead being true is a logical property and its role and use is exhausted by its predicate '... is true'. So, in one sense he is an ontological primitivist about truth. But being true for Horwich does not have a robust nature like that of Merrick's primitivism. So we need another distinction: let us distinguish between strong and weak ontological primitivism about truth. Strong ontological primitivism takes being true as substantive whereas weak ontological primitivism takes being true as non-substantive. Horwich is a weak ontological primitivist and Merricks is a strong ontological primitivist.

Merricks' defence of primitivism is supported by a sustained attack against competing theories of truth and a book-length criticism of truthmaking. ${ }^{2}$ For Merricks, the final dispute is between primitivism and Paul Horwich's (1998) minimalism. Merricks argues that since we should reject minimalism, we should adopt primitivism. This is where I enter the dialectic. I think Merricks' arguments can be resisted and a critical discussion of his version of primitivism reveals that being true, that is the property and not the concept, is rendered mysterious and suspicious. Primitivism entails that being true mysteriously 'points towards' reality and 'points beyond' itself in an unacceptable way.

This paper is an examination of Merricks' primitivism about truth. It is not a comprehensive discussion of primitivism in general and in objecting to Merricks' primitiv-

\footnotetext{
${ }^{2}$ I do not discuss theories of truthmaking in this paper as I focus on Horwich's minimalism and Merricks' primitivism, although I give some remarks in the final section. For truthmaking see (Armstrong 2004).
} 
ism I am merely rejecting his version of the view. ${ }^{3}$ My dialectic is strictly confined to Merricks' primitivism and Horwich's minimalism. Hence I do not consider other variants of primitivism or minimalism. This is after all how Merricks constructs the debate. His defence, arguments for his version of primitivism and objections against minimalism have received little to no attention in the literature. So if my critique of Merricks is correct, this paper advances an under-discussed dialectic and addresses a yet unexamined position in the subject of truth in philosophy.

In what follows, I present Merricks' general argument against competing theories of truth and set up the debate between his version of primitivism and Horwich's minimalism $(\$ 2)$. I argue that Merricks' objection against minimalism does not succeed $(\mathbb{3})$. I then present his version of primitivism $(\mathbb{S})$ and argue that it entails that being true is a mysterious and suspicious property $(\$ 5)$. I critically discuss a reply $(\mathbb{S} 6)$ and then conclude that within the context of the debate between minimalism and primitivism we should not adopt Merricks' primitivism ( $\mathbb{S} 7$ ).

\section{Merricks' Primitivism and Horwich’s Minimalism}

Merricks (2007) argues that all relational theories of truth and truthmaking are false because there are some truths that are true in virtue of no relation to some entity or proposition, whether that relation is one of utility, coherence, correspondence, etc. ${ }^{4}$ Since all relational theories of truth are false, we are left with non-relational theories of truth. According to Merricks, there are two non-relational theories on offer, namely, minimalism and primitivism. So the debate between non-relational theories is a dispute between primitivism and minimalism. Let us consider the relevant differences between minimalism and primitivism in order to understand the debate. Recall the debate here is between Merricks' primitivism and Horwich's minimalism. From now on when I use the term 'primitivism' it refers to Merricks' version of primitivism.

Horwich says truth has no underlying robust nature. But although it has no underlying nature, there is the property being true. It is just that being true is not a robust property. So Horwich's denial of primitivism can be understood as a denial of strong ontological primitivism. Now the core of minimalism is the equivalence schema:

(E) The proposition that $\mathrm{p}$ is true just in case $p$.

Minimalists, true to their name, state that our theory of truth is nothing more than:

(MT) The proposition that quarks really exist is true if and only if quarks really exist, the proposition that lying is bad is true if and only if lying is bad, ... and so on (Horwich 1998, 5).

According to Horwich, we begin with instances of (E), e.g., the proposition that snow is white is true just in case snow is white, and then show how our acceptance of

\footnotetext{
${ }^{3}$ For a recent defence of primitivism, see (Asay 2013). In this paper I am merely concerned with Merricks' version of primitivism.

${ }^{4}$ Merricks also discusses and rejects the identity theory of truth. He rejects the identity theory before narrowing the debate down to minimalism versus primitivism. So the identity theory is not relevant to our main discussion.
} 
these instances and in fact the infinite conjunction of these instances 'constitutes' our concept of truth. This does not amount to a conceptual analysis in an explicit sense. It is merely an implicit definition if anything. And the fact that we do not have an explicit definition of the concept does not entail that we cannot grasp it. The way we grasp the concept of truth, according to Horwich, is by our disposition to accept instances of (E). It is taken as a basic explanatory fact that we have this disposition (Horwich 1998, 126). Instances of (E) are taken as conceptually basic and known a priori. This entails that the story about truth is incomplete. But, as David Lewis points out, 'there is no need to complete it. The untold part merely repeats the same pattern over and over, so a tiny sample tells us all we need to know' (2001, 603). Our ability to go on adding instances of the same pattern is grounded in the fact that the notion of a proposition is prior to the notion of truth. As Horwich writes,

... minimalism entails that the notion of proposition [does] not depend on the notion of truth. For the minimalist's direction of conceptual priority is the other way round: in so far as our concept of truth is constituted by our acceptance of instances of 'The proposition that $p$ is true iff $p$ ', we must already be capable of grasping propositions (1998, 16-7).

In short, we need the notion of a proposition to be prior to the notion of truth since (MT) is conceptually basic and our acceptance of instances of (E) constitutes our concept of truth. To recap, the following features are a sufficient characterisation of minimalism: 1) being true exists as a non-substantive property, 2) (MT) is conceptually basic and known a priori, and 3 ) the notion of a proposition is prior to the notion of truth.

Primitivism, put briefly, is the view that being true is a primitive, non-intrinsic property had by some propositions and not others. Since being true is not analysed in terms of any further entity, it is not analysed in terms of some relation. Thus, primitivism counts as a non-relational account of truth. ${ }^{5}$ There are two relevant differences between minimalism and primitivism. First, minimalists take instances of $(\mathrm{E})$ as brute and our disposition to accept instances of (E) as constituting our concept of truth, whereas primitivists take our grasping of being true as fundamental and that which grounds our understanding of (MT). Merricks claims that by grasping the property being true we understand instances of (E). He says, '[t]his [grasping] allows us to recognize some of what being true implies' (2007, 190). Merricks compares our grasping of being true with the property of being self-identical. By grasping the property of identity, we recognise that it implies that identity is reflexive, transitive and symmetric. With respect to truth, Merricks continues, '[a]mong its implications are the biconditionals included in MT, some of which we understand and can articulate' $(2007,190)$; he then goes on to say 'our ability to continue to articulate the biconditionals that constitute [(MT)] is rooted in our grasp of the property of being true' (2007, 191, my italics). By contrast, Horwich says that taking instances of the equivalence schema as conceptually basic provides us with the correct direction of explanation. Other theories of truth, he states, do not provide 'a good account of why it is that instances of the equivalence schema

\footnotetext{
${ }^{5}$ Given this characterisation of primitivism, being true cannot be rendered a primitive relation. This makes sense since, as Merricks notes, being true is monadic and so not a relation (although he thinks it is non-intrinsic). I bracket relational theories in what follows and merely focus on non-relational accounts of truth.
} 
are true. Minimalism involves a reversal of that explanatory direction' (Horwich 1998, 11-12).

Second, minimalists take the 'ontological status' of being true as non-substantive. The minimalist is nothing more than a weak ontological primitivist given the distinctions drawn in the Introduction. On the other hand, the primitivist claims that being true is a substantive property. So Merricks is a strong ontological primitivist. Indeed, primitivists like Merricks must be committed to the claim that being true is a substantive property since being true is used to explain how we understand instances of $(\mathrm{E})$. Being true is doing more work than merely being the referent of the predicate '... is true'. If it is doing real work in the theory, it is a substantive property. ${ }^{6}$

You might think this yields a real difference and hence disagreement between primitivism and minimalism. However, Merricks thinks Horwich must deny the existence of being true to make minimalism consistent with the denial of primitivism. The argument is that Horwich denies primitivism, so he thinks being true is not unanalysable but yet he says that truth is not susceptible to analysis. Merricks concludes that the way out of the inconsistency for Horwich is to deny the existence of being true. Merricks writes,

The only way to render these two claims consistent is to deny that there is any such property at all. For only then can it be false that being true is analysable and also false that being true is primitive $(2007,189)$.

But Merricks' objection is misplaced due to a misunderstanding of Horwich. According to minimalism, the concept of truth is primitive in a specific sense, namely, there is no explicit definition of the concept. Horwich thinks the concept of truth is implicitly defined by the equivalence schema. In addition, it is one thing to say that being true has no analysis and quite another to say that the concept of truth is primitive. Horwich's denial of primitivism thus amounts to a denial of strong ontological primitivism while accepting that the concept of truth is primitive in the sense that there is no explicit analysis consisting of necessary and sufficient conditions.

So we have a genuine disagreement between Merricks' primitivism and Horwich's minimalism. Merricks thinks by grasping being true we understand some of the biconditionals of (MT) and Horwich thinks we begin with some of the biconditionals of (MT) as conceptually basic and then provide an implicit definition of the concept of truth. The dispute between minimalism and primitivism boils down to the explanatory direction between being true and (MT). Either being true comes first, then (MT) or (MT) comes first, then the concept of truth.

\section{Merricks against Horwich's Minimalism}

Merricks argues that primitivism is to be preferred over minimalism because minimalism does not properly explain how we understand instances of (E). If we begin with the infinite series of instances of (E), i.e., <cats purr> is true iff cats purr, and so on, then we cannot explain how we add further instances of (E) to the infinite series. Thus,

\footnotetext{
${ }^{6}$ Primitivism is typically classified as a robust theory independent of this argument. See (Lynch 2001, 4).
} 
it is mysterious that we know to add $<$ dogs bark $>$ is true iff dogs bark. And therefore it is equally mysterious how the infinite series constitutes our concept of truth (Merricks 2007, 190). We should not accept this mystery. Hence we should reject minimalism. Merricks writes,

Given MT, it is mysterious that we know to add that that dogs bark is true if and only if dogs bark. More generally, it is mysterious that we know how to 'go on' adding the biconditionals that constitute MT. In particular, if MT is right, we cannot explain our ability to 'go on' by way of our understanding MT. That 'explanation' is viciously circular, since to understand MT just is to be able to 'go on' $(2007,190)$.

We can construct the objection as follows:

(P1) (MT) is conceptually basic.

(P2) If (MT) is conceptually basic, it is mysterious that we know to add instances of $(\mathrm{E})$.

(C) Thus, it is mysterious that we know to add instances of (E).

The argument is valid and (P1) is true according to minimalism. So, the objection rests on the truth of (P2). Why should we accept (P2)? Merricks' reason for accepting (P2) seems to be based on the claim that our understanding of (MT) consists in our ability to go on adding instances of (E). He writes, 'our being able to 'go on' in this way counts as our understanding MT' $(2007,189)$. If our ability to 'go on' adding instances constitutes our understanding of (MT), then it is mysterious that we know to add an instance of (E) because we cannot explain this fact since it is equivalent to our understanding of (MT) which is what we are taking as brute. Thus, according to Merricks, if (MT) is conceptually basic, it is mysterious that we know to add instances of (E).

But why should we accept that our ability to 'go on' adding instances of (E) constitutes our understanding of (MT)? Merricks gives no reason to accept this claim and there are reasons to believe that our understanding of (MT) is not exhausted by our ability to 'go on' adding instances of (E) but rather contains it as a mere part. Our understanding of (MT) is based on the fact that we understand what instantiation means, the notion of a proposition and the fact that we can simply plug into (E) any instance we wish. To illustrate, we understand that <cows moo $>$ has the property being true because we understand that <cows moo $>$ is true iff cows moo. This requires that we understand the notion of instantiation and the notion of a proposition. But, since (MT) is an infinite series of instances of $(\mathrm{E})$, our understanding of (MT) requires the added component of understanding the concept of 'and so on'. Our understanding of 'and so on' is our grasping of the repetition of the same pattern. This is nothing more than knowing how to add instances of (E). Thus, our understanding of (MT) is not merely our ability to 'go on'. Rather our ability to 'go on' is part of our understanding of (MT).

Since the minimalist takes the notion of a proposition as primitive, we can accept this explanation. Therefore, we can reject Merricks' claim that our ability to 'go on' or our understanding of what 'and so on' means constitutes our understanding of (MT), and therefore reject the truth of (P2). So, Merricks' objection fails. Moreover, we 
should accept that the direction of explanation is from (MT) to being true since it is not plausible to suppose that the direction of explanation is from being true to (MT). Recall that Merricks thinks we grasp being true, realise it implies instances of (E), and that this is a sufficient explanation of our understanding of (MT). If we reject that our understanding of (MT) is constituted solely by our ability to 'go on' adding instances of (E), our knowing whether a proposition instantiates being true depends on its corresponding instance of (E). As Merricks admits,

I know that humans exist, and I know that that humans exist is true if and only if humans exist; this is how I know that the proposition that humans exist exemplifies the property of being true $(2007,190)$.

So even Merricks thinks we know that a proposition has the property being true based on the fact that we know the corresponding instance of $(\mathrm{E})$. But, if we know that a proposition has the property of being true because we know its corresponding instance of (E), we have appealed to an instance of (E) to explain how we know being true. To say that we know a proposition instantiates being true because we know its instance of $(\mathrm{E})$ requires the notion of a proposition to be prior to the notion of truth since any instance of (E) is known a priori and so known in virtue of grasping the notion of a proposition. If we require the notion of a proposition to be prior to the notion of truth, we must accept the minimalist's direction of explanation.

\section{Merricks’ Primitivism}

According to Merricks, being true is a primitive or fundamental property of propositions. But what does it mean to say that a property is primitive or fundamental? What it means for a property to be primitive can be understood by determining what it means for a property to be non-primitive. For Merricks, 'these [latter] properties are built up out of, or analysable in terms of, or reducible to, other properties' $(2007,49)$. He provides an example:

Suppose that being a bachelor is analysed as (or reduced to) being unmarried, being eligible, and being male. Then, necessarily, the exemplification of being a bachelor supervenes on the exemplification of being unmarried, being eligible, and being male $(2007,49)$.

The fact that some particular exemplifies being a bachelor entails that being a bachelor has a local supervenience base. ${ }^{7}$ Thus, being a bachelor has a local supervenience base just in case the instantiation of being a bachelor by a person is necessitated by the instantiation of being unmarried, being eligible and being male by that same person. More generally, an analysis of being $F$ entails that there is, of necessity, a local supervenience base for being $F$. If being $F$ has a local supervenience base, it is not primitive. If being $F$ is not primitive, it must supervene on the properties or relations that are part of its analysis or reduction. If being $F$ fails to supervene on some other properties or relations, or being $F$ fails to have a local supervenience base, it is primitive. Thus, a primitive property is a property that lacks a local supervenience base; primitive properties do not supervene on any further properties (Merricks 2007, 54).

\footnotetext{
${ }^{7}$ Local supervenience is to be contrasted with global supervenience, the latter being concerned with discernibility between worlds while the former is about supervenience within a world.
} 
According to Merricks, being true is a primitive property. Thus, being true does not have a local supervenience base. So, it is not the case that necessarily if $<\mathrm{p}>$ has (say) being $G, H, I$, then $<\mathrm{p}>$ has the property being true, where being $G, H$, and $I$ are putative properties that might constitute an ontological analysis of being true. Or, assuming a relational account of truth, if being true is primitive, it is not the case that necessarily if $\langle\mathrm{p}\rangle$ is related to $p$ in virtue of $R$, then $<\mathrm{p}>$ has the property being true.

Merricks argues that being true is primitive. Merricks' argument for the claim that being true is primitive runs as follows. If being true is non-relational, then any analysis of being true must be in terms of non-relational properties of truths. Since no analysis that fits this restriction looks promising, being true is primitive. However, this argument is not relevant here because minimalism accepts the conclusion even though it rejects that being true is substantive. The argument in general does little work dialectically speaking since relational theorists deny the premise that being true is nonrelational. Finally, the argument has been shown by Jonathan Schaffer to equivocate between a conceptual and ontological analysis of truth (Schaffer 2008, 309, n. 13). Merricks blurs the distinction between concept and property. The fact that being true is primitive does not entail that our concept of it is primitive and vice-versa.

Putting Merricks' argument for his version of primitivism aside, he claims not only that being true is primitive but that being true is a non-intrinsic property. Typically, a non-intrinsic property is a property that is had by an individual because the individual stands in some relation to some other object. For example, being a wife is non-intrinsic since its instantiation depends on the marriage relation that holds between husband and wife. However, Merricks thinks there are some properties that are non-intrinsic, but instantiated by an entity in virtue of some other entity without any relation holding between the two entities. There are, according to Merricks, non-relational but nonintrinsic properties and being true is one of them. He writes,

[Being true] is not intrinsic. For whether a proposition exemplifies being true is often a matter of how things are around it. For example, whether that dogs bark is true is not only a matter of what that proposition is like, but also a matter of whether there are any dogs and what those dogs do $(2007,182)$.

The use of the term 'monadic' by Merricks is non-standard. Typically, if a property is monadic, it does not entail that the property is non-relational. For example, being an uncle is monadic but not non-relational. Being an uncle is monadic in virtue of being a property that has one 'slot' or has as its logical form 'one-place' which need only be 'saturated' by one object. This non-standard use of 'monadic' is not itself objectionable. But note well that Merricks uses the terms 'monadic' and 'non-relational' interchangeably.

Since primitivism is consistent with truth depending on reality in the trivial and noncontroversial sense that $<\mathrm{p}>$ is true because $\mathrm{p}$ (cf. Merricks 2007, 186), primitivism entails that being true is a non-relational, non-intrinsic primitive property that is instantiated by some propositions and not others because of what a given proposition is like and what exists 'around' it. But no relation is posited to elucidate this claim. Whether certain propositions such as necessary ones are true or not won't be a matter of what goes on in the physical world. Necessary propositions in virtue of what they are like also stand in no relation to the world. So, a (contingent) proposition having 
the property being true does not stand in a relation to anything yet it having being true is a matter of what goes on in the world.

\section{Against Merricks’ Primitivism}

Merricks' primitivism is subject to a familiar objection that charges primitivism with leaving the concept of truth shrouded in mystery. Horwich puts the objection briefly as follows:

[Consider the view] that truth is an indefinable, inexplicable quality that some propositions simply have and others simply lack-a fundamental property of which no account can be provided. This gives a sense of impenetrable mysteriousness to the notion of truth and can be the resort only of those who feel that the decent alternatives have been exhausted (1998, 9-10).

Horwich's objection is that if being true is primitive and taken as substantive, then the concept of truth is mysterious. Therefore, we should not accept that being true is a primitive substantive property. The objection is targeted at strong ontological primitivists about truth. But its main weakness is that it rejects strong ontological primitivism on the grounds that it renders the concept of truth as mysterious. Merricks can easily reply that we do in fact grasp the concept of truth even though the property being true is primitive and so the concept is not mysterious, which he does (Merricks 2007, 185). Just because being true is primitive it does not mean we cannot grasp the corresponding concept. So the objection has an invalid premise.

But we can bolster this objection by arguing that if being true is a substantive primitive property, then the property itself (i.e., being true) and not the concept is mysterious. We can develop this objection by arguing on metaphysical grounds that being true is mysterious and suspicious given Merricks' primitivism. Horwich's objection is too brief and does not get to the heart of the issue, which is really an issue about the metaphysical nature of properties and not about our concepts of the subject matter. As we will see, my version of the argument is distinct from Horwich's and so is a new argument against primitivism, or at least against Merricks' version. Moreover, Horwich's overall position against primitivism is not that the view is false but rather that it in inadequate because it fails to fulfil explanatory demands concerning instances of the equivalence schema (see Horwich 1998, 11-2). We can do better here, I submit, by showing that there is something ontologically repugnant with the property being true, according to Merricks' primitivism.

Here is my developed version of the objection. If we accept the claim that an object can have a property because of some other thing, then, clearly, we admit the object in question which has the property is related to the other thing in some way. If we accept that an object having a property is related to some other thing, then intuitively it stands in some relation to that other thing. If we accept the fact that whether being true is instantiated or not is a matter of something in the world, being true is related and hence stands in some relation to some entity or entities in the world. This is the intuitive claim concerning our concept of truth if we accept that which propositions are true is a matter of what goes on around them. This is the intuitive understanding of the dyadic expression '... is a matter of ...'. To see this, consider necessary truths. If 
necessary truths are not true because of the world while contingent truths are, then we need to explain this difference by positing a relation in the latter case that does not hold in the former. If there is no relation in both cases, where is the difference? If it is a matter of what is around contingent propositions that determines whether they have being true, then intuitively there is a relation to account for this fact. Indeed, if we accept the intuition that truth depends on being, even in a trivial and noncontroversial sense, then intuitively truth,

... has to do with what the truth bearer is about, rather than some 'internal' or 'intrinsic' feature of the truth bearer, ... truth has to do with the relation of a potential truth bearer to a reality beyond itself (Alston 1996, 7-8).

According to Merricks, there is no relation with which a proposition and the world can be intuitively related. Hence, Merricks' use of the dyadic expression '... is a matter of ...' is counter-intuitive. However, if we accept Merricks' counter-intuitive understanding of '.. is a matter of ...', being true has a mysterious nature of 'pointing towards' certain entities in the world which are mysteriously related to certain propositions without a relation that stands between a truth and the world. Worse still, being true not only 'points towards' other entities in a mysterious way (for there is no relation to explain why this is so) it also has a brute nature of 'pointing beyond' itself. If being true 'points beyond' itself or its instances, then being true is also a suspicious property. Property $F$ is suspicious if the instances of $F$ point beyond what instantiates them. To use Ross Cameron's (2011) example, suppose I instantiate being such as to have been a child, a property that is directed towards the past. Suppose further that we take this property as primitive. It follows that we have no explanation as to why this property has the feature of being directed towards the past and so no relation to ground this property's nature. The primitive property being such as to have been a child is suspicious because my instantiation of it right now is not part of my intrinsic nature right now.

Analogously, being true is directed towards what truth-bearers are about. Whether being true is instantiated is a matter of what goes on around the proposition. But if so, then being true points beyond its instances and points towards other entities distinct from its instances (i.e., distinct from the propositions that instantiate being true). Now, we could give an explanation of the 'directedness' of being such as to have been a child if we posited some past time at which there exists some entity that I am currently related to. We could also give an explanation of the 'directedness' of being true if we posited some relation between truth and reality. But this sort of explanation is exactly what primitivism rules out. Thus, being true is mysterious and suspicious. Merricks rejects suspicious properties for the same reasons I just mentioned (see Merricks 2007, 60). So, if being true is suspicious according to primitivism, Merricks should also reject primitivism.

To be clear, I am not arguing that being true is mysterious because it is primitive. Of course, every theory must have primitives and given that primitives lack the illuminating explanation that non-primitives enjoy we are denied a particular insight into their nature. We are therefore at the mercy of the intuitive concepts of the things we take as primitive. Following Lewis, I think it is best to take familiar things as primitive and avoid 'unduly complex' and 'unduly mysterious' primitives (Lewis 1983, 353). My objection is that the way Merricks takes being true as primitive (i.e., as non-relational 
and non-intrinsic) renders the property unduly complex and mysterious in an objectionable way. Explanation must bottom out somewhere in the primitives of our theory. But this does not entail that we should take anything as primitive or neglect the pursuit of finding which primitives are more appropriate or never scrutinise the primitives of our most plausible theories. We must accept some primitives but being true (qua substantive property) is not one of them.

Given this counter-intuitive consequence of primitivism, we are left wondering why there simply is no connection between truth and entity. If the world affects truth, then there must be a reason why this is so. This state of wonderment is caused by the mysteriousness of Merricks' primitivism. Appealing to talk of '.. is a matter of ...' without positing a relation won't solve the mystery. I am not denying the existence of nonrelational non-intrinsic properties. They may, for all I know, exist. What I am denying is the characterisation of a particular candidate non-relational non-intrinsic property, namely, being true as a primitive property. Being true is not a non-relational nonintrinsic property.

\section{A Possible Reply by Merricks}

Merricks might reply to this objection by saying that being true does not have the repugnant nature I am attributing to it since these kinds of properties are more common than we realise. One example of an allegedly acceptable non-relational non-intrinsic property is being such that there is nothing more in the universe. Let us consider an instance of this property. Suppose there is a world in which there is only one thing and that this thing has no proper parts. Call it 'Joe'. Joe instantiates the property being such that there is nothing more in the universe for there is nothing else around in this world, including any parts that Joe might have. If Joe instantiates being such that there is nothing more in the universe, then it is not because of anything around Joe since nothing else exists. Thus, being such that there is nothing more in the universe is nonrelational. However, being such that there is nothing more in the universe is not intrinsic since whether Joe has this property is a matter of whether there exist other things around Joe. So, being such that there is nothing more in the universe is of the same nature as being true. Since Merricks' opponents such as truthmaker theorists require such properties in order to provide truthmakers for negative existentials and generalisations, then, Merricks might say, there is nothing wrong with saying that being true has a similar nature (see Merricks $2007,182-3){ }^{8}$

But this response is unsatisfying for the following reasons. First, it is dialectically weak since we are not considering primitivism versus relational accounts of truth. Rather we are considering primitivism versus minimalism, the latter of which does not require the postulation of properties such as being such that there is nothing more in the universe. The minimalist would applaud this concession since they would say Mer-

\footnotetext{
${ }^{8}$ I have not said much about theories of truthmaking. But just briefly, the truthmaker theorist claims that what it is for a truth to be true is for a truth to be made true by a truthmaker. In other words, if entity $t$ makes $p$ true, then it is impossible for $t$ to exist and $p$ be false. If we believe that every truth must have a truthmaker, then negative truths and generalisations must have truthmakers. Armstrong argues that we need a 'totality' state of affairs in addition to first-order states of affairs as truthmakers for such truths. See (Armstrong 2004, ch. 6).
} 
ricks is just admitting he indulges with bad company. If primitivism must admit these sorts of properties, we should reject primitivism and relational accounts of truth for the same reason. ${ }^{9}$

Second, even if Merricks claims he is not alone in positing non-relational nonintrinsic properties, he still lacks an explanation for why being true is non-relational and non-intrinsic, while the truthmaker theorist can provide an explanation for the nature for their properties. If the truthmaker theorist can provide some kind of explanation, they can make intelligible these sorts of properties, even though they are of a peculiar kind. Without an explanation, Merricks' attempts to find company with some of his opponents leave him in isolation.

The truthmaker theorist can give the following explanation. Being such that there is nothing more in the universe is non-relational and non-intrinsic because any instance of it necessarily excludes other entities from existing. Let us consider a different but similar property, the property of being other than a bunyip (bunyips are mythical creatures that allegedly lurk in the billabongs and creeks of Australia). Now suppose we have the state of affairs of everything being other than a bunyip. Call this state of affairs ' $G$ '. G cannot exist in worlds where bunyips exist, and in every world where bunyips do not exist $G$ must exist. Thus, necessarily $G$ exists iff bunyips do not exist and necessarily bunyips exists iff $G$ does not exist. In other words, it is part of the nature of $\mathrm{G}$ to exclude bunyips. Thus, there is a necessary connection between $\mathrm{G}$ and the absence of bunyips. The appeal to necessary connections is controversial. But the point is that the relevant necessary connection explains why being other than a bunyip and being such that there is nothing more in the universe are non-relational and non-intrinsic.

In the case of being true, the appeal to necessary connections is not part of the explanation for why it is non-relational and non-intrinsic. Being true is non-intrinsic because whether or not a proposition has the property is a matter of what is or what is not around it. End of story. Perhaps, the fact that a proposition instantiates being true necessarily excludes other entities from existing, but this is not the reason why being true is non-intrinsic. And the fact that <dogs bark> instantiates being true does not exclude the existence of dogs that do not bark. Hence, Merricks cannot appeal to properties such as being such that there is nothing more in the universe to draw the analogy he requires, for there is none.

Overall, our main sentiment concerning truth is that truth is often a matter of what goes on around the things that are said to be true. This basic intuition concerning truth has been explained, to the dissatisfaction of many, by invoking some relation between truths and entities. Given this dissatisfaction and the fact that we recognise this intuition, if we fail to explain it, we admit that being true has some, as Horwich puts it, 'peculiarly enigmatic character [such that] a conception of its underlying nature appears to be at once necessary and impossible' (1998, 1-2, my italics). If we accept the fact that truth is a matter of what is around the things that are said to be true, but that any relational account of this intuition fails, then being true is clouded in mystery since we endow it with a brute nature that mysteriously points beyond itself and towards other entities. And this is exactly what Merricks concedes when he claims that being

\footnotetext{
${ }^{9}$ Merricks also thinks being such that there is nothing more in the universe is a suspicious property (Merricks 2007, 60). So it is unclear why he warms us up to the idea of non-relational non-intrinsic properties by appealing to properties he outright rejects.
} 
true is had by a proposition because of what is around it, but that this is not because of some relation between that proposition and some entity or entities. If we admit being true has this peculiar nature, we have embraced nothing more than the primordial fact that the nature of truth is a mystery, something which possesses a 'peculiarly enigmatic character'. We are in the business of reducing mystery where possible. So we should reject Merricks' primitivism.

\section{Conclusion}

I argued that Merricks' primitivism renders being true as mysterious and suspicious. So we should reject his primitivism, although I make no final judgements about primitivism in general. For all I have said there could be a plausible version of primitivism. But it is not Merricks'. I further argued that Merricks' objections against minimalism do not succeed since by his own lights he must take the notion of a proposition as prior to the notion of truth and accept the fact that we know being true is instantiated by $<p>$ because we know that $\langle\mathrm{p}>$ is true iff $\mathrm{p}$. The dialectic we began with assumed that all relational theories of truth are false, leaving the debate between primitivism and minimalism. Given that I argued Merricks' primitivism should be rejected, minimalism seems to be the standing victor. More can be said in favour of minimalism. We have further reason to adopt it if being true is merely a logical property or has little 'metaphysical weight' (Horwich 1998, 146; cf. Smith 2003, 43). As Horwich argues, '[g]iven the function of truth, we may infer that the general facts which we need the concept of truth to articulate are not really about truth; therefore their explanation would not be facilitated by an account of truth's underlying nature' (1998, 145, his italics). If we undermine the need to appeal to the underlying nature of truth, it makes no sense to assume that the concept of truth is itself substantive. Thus, we have no reason to claim that being true is a substantive property, and so another reason not to accept Merricks' primitivism.

It seems that when it comes to theories of truth minimalism is on strong footing. ${ }^{10}$ But there is room for a theory of truthmaking to complement minimalism if the theory of truthmaking in question does not advertise itself as a competing theory of truth. It is plausible to suppose that we can compose a 'hybrid' theory based on the assumption that there is a genuine difference between what it is for a truth to be true and what it is for a truth to be made true (Mellor 2009, 274-5). Put differently, the truthmaking project need not provide a theory of truth, but instead a theory of truths (Forrest 2006, 138). Therefore, we can endorse instances of (E) while acknowledging that (MT) tells us about truth but not about how truths are made true. The project of truthmaking would then sit underneath a theory of truth by playing the role of determining the elements of our fundamental ontology. Of course, Merricks rejects truthmaking and therefore rejects truthmaking playing any sort of theoretical role. For the hybrid theory to succeed his critique of truthmaking must be answered and I have done nothing here to circumvent this particular situation. ${ }^{11}$ That, however, is the subject of another paper.

\footnotetext{
${ }^{10}$ For further defences of other varieties of minimalism, see (Alston 1996; Mackie 1973, 17-63).

${ }^{11}$ Merricks' main argument against truthmaking is that some truths have no truthmakers. So, truthmaking is false. This argument depends on the claim that every truth must have a truthmaker. Merricks ar-
} 
Acknowledgements Thanks to Peter Forrest, André Gallois, Matt Leonard, Hugh Mellor and Joshua Spencer for comments and discussion on earlier versions of this paper. I also thank the audiences at the Pacific APA, 7 April 2012, Seattle, WA, and the University of New England, Armidale, NSW, Australia, 24 June 2010.

\section{References}

Alcoff, Linda Martin. 1996. Real Knowing: New Versions of the Coherence Theory. Ithaca: Cornell University Press.

Alston, William P. 1996. A Realist Conception of Truth. Ithaca: Cornell University Press. Armstrong, D. M. 2004. Truth and Truthmakers. Cambridge: Cambridge University Press. Asay, Jamin. 2013. The Primitivist Theory of Truth. Cambridge: Cambridge University Press.

Cameron, Ross P. 2011. Truthmaking for Presentists. In Oxford Studies in Metaphysics vol. 6, ed. K. Bennett and D. Zimmerman. Oxford: Oxford University Press.

Forrest, Peter. 2006. General Facts, Physical Necessity, and the Metaphysics of Time. In Oxford Studies in Metaphysics vol. 2, ed. D. Zimmerman. Oxford: Clarendon Press.

Horwich, Paul. 1998. Truth 2nd ed. Oxford: Clarendon Press.

James, William. 1909. The Meaning of Truth. Cambridge, MA: Harvard University Press.

Lewis, David. 1983. New Work for a Theory of Universals. Australasian Journal of Philosophy 61(4): 343-77.

-. 2001. Truthmaking and Difference-Making. Noûs 35(4): 602-15.

Lynch, Michael P. 2001. Introduction: The Mystery of Truth. In The Nature of Truth: Classic and Contemporary Readings, ed. M. P. Lynch. Cambridge, MA: MIT Press.

Mackie, J. L. 1973. Truth, Probability and Paradox. Oxford: Clarendon Press.

Mellor, D. H. 2009. Truthmakers for What? In From Truth to Reality: New Essays in Logic and Metaphysics, ed. H. Dyke. London: Routledge.

Merricks, Trenton. 2007. Truth and Ontology. Oxford: Clarendon Press.

Moore, G. E. 1953. Some Main Problems of Philosophy. London: Allen and Unwin.

Russell, Bertrand. 1912. Problems of Philosophy. Oxford: Oxford University Press.

Schaffer, Jonathan. 2008. Truth and Fundamentality. Philosophical Books 49(4): 302-16.

Smith, Peter. 2003. Deflationism: The facts. In Real Metaphysics: Essays in Honour of D. H. Mellor, ed. H. Lillehammer and G. Rodríguez Pereyra. London: Routledge.

Tallant, Jonathan. 2010. There's No Existent like 'No Existence' like No Existent I Know. Philosophical Studies 148(3): 387-400.

gues that if we accept truthmaking, we should accept that every truth must have a truthmaker (Merricks 2007, 24-6). I would reject this inference and Merricks' defence of it, and so deny that every truth must have a truthmaker. For discussion, see (Tallant 2010). 